\title{
Three different diagnoses of similar presentations with fever, confusion and rigidity
}

\author{
RP Bandara, A Ellepola
}

\section{Abstract}

Patients presenting with acute muscular rigidity, fever and confusion is a management challenge in medical practice. It could be a potentially lethal case with poor prognosis. The authors of this article highlight the importance of appropriate assessment of patients to arrive at a correct diagnosis. Clinicians need to be mindful of subtle differences between differential diagnoses. Diagnostic guidelines and criteria assist in differentiating conditions. Management and outcome depends largely on the aetiology of the manifestations. The three cases reported in this paper presented with the symptom triad of muscular rigidity, fever and confusion. However, the causative conditions were different from one case to the other. Heat stroke, serotonin syndrome and neuroleptic malignant syndrome (NMS) were the diagnoses arrived at. Two patients recovered completely, while the other patient succumbed.

Key words: Opisthotonus, rigidity, neck stiffness, antidepressants, antipyretics, Babinski sign, serotonin syndrome, neuroleptic malignant syndrome

\section{Abbreviations}

GCS: Glasgow coma scale, $\mathrm{O}_{2}$ : Oxygen, F: Fahrenheit, ${ }^{\circ} \mathrm{C}$ : Centigrade, ALT: Alanine transaminase, AST: Aspartate aminotransferase, CSF: Cerebrospinal fluid, $\mathrm{Hb}$ : Haemoglobin, WBC: White blood cell

SLJ Psychiatry 2019; 10(2): 17-21

\section{Introduction}

Acute rigidity presenting together with confusion and fever, can be a potentially life threatening, rare condition. Diagnosis of the condition could vary from case to case. The symptoms and signs could be due to a primary or a secondary cause. Appropriate treatment following a careful diagnosis is mandatory to save the patient's life. A multidisciplinary and holistic management is necessary in most of the cases. We describe three patients who presented with similar symptoms and signs to a medical unit, and who were later diagnosed with three different medical conditions.

\section{Case Report 1}

A 60-year old male, a diagnosed patient of depression, had been started on haloperidol by a general practitioner due to recent altered behaviour. He was subsequently admitted to the hospital with a five-day history of high grade fever, muscle rigidity and confusion.

On admission, the patient was confused, with a GCS $8 / 15$, and a high swinging fever. The patient had neck stiffness with generalized muscle rigidity. All reflexes were exaggerated with bilateral negative Babinski sign. No cranial nerve palsies were noted. His pulse rate and blood pressure were fluctuating throughout the hospital stay. Other systems were clinically normal.

Investigations on admission showed a serum creatinine of $1.2 \mathrm{mg} / \mathrm{dl}$, ALT - $187 \mathrm{u} / \mathrm{l}$, AST - $273 \mathrm{u} / \mathrm{l}$, and blood urea $-9.5 \mathrm{mmol} / \mathrm{l}, \mathrm{Hb} 13.6 \mathrm{~g} / \mathrm{dl}$, WBC count $14.0 \times 10^{9} / 1$ with predominant neutrophils, and platelets - $148 \times 10^{9} / 1$. CSF analysis was normal.

The creatine kinase level was 2873 U/l (55-170 U/l) on day 2 of admission.

A provisional diagnosis of neuroleptic malignant syndrome (NMS) was made. Oral bromocriptine and broad spectrum intravenous antibiotics were started. Vital parameters were closely monitored in the high dependency unit.

The patient developed severe hypotension and resistant sinus bradycardia on the fifth day of admission and passed away despite maximum care. 


\section{Case Report 2}

A 37-year old male patient presented with recurrent attacks of generalized tonic clonic fits for three days duration. He had been agitated and confused, with a one-day duration of profuse diarrhoea and sweating. He had been recently diagnosed as having depression and was on fluoxetine $20 \mathrm{mg}$ mane and imipramine $100 \mathrm{mg}$ nocte.

On admission, he was drowsy with a GCS of 6/15, his blood pressure was $140 / 90 \mathrm{mmHg}$, and pulse rate $100 / \mathrm{min}$. He was febrile with a temperature of $40^{\circ} \mathrm{C}$. He had generalized body rigidity with hyper-exaggerated reflexes and bilateral lower limb clonus. His pupils were dilated with a sluggish light reflex, and the abdomen was distended, with excessive tympanic bowel sounds.

A tentative diagnosis of serotonin syndrome was made and the anti-depressive treatment was omitted. He was started on antypyretics to control the temperature. Antiepileptics were given to control the seizures. Intravenous fluids were started to achieve adequate urine output. Oral cyproheptadine was started to antagonize the action of serotonin. Antibiotics were given to cover the possible aspiration pneumonia.

Investigations on admission showed a serum creatinine of $1.3 \mathrm{mg} / \mathrm{dl}$, ALT - $230 \mathrm{u} / \mathrm{l}, \mathrm{AST}-113 \mathrm{u} / \mathrm{l}$, and blood urea $-10.1 \mathrm{mmol} / \mathrm{l}$. His $\mathrm{Hb} 11.3 \mathrm{~g} / \mathrm{dl}$, and $\mathrm{WBC} 8.0 \times 10^{9} / \mathrm{l}$ with predominant neutrophils, platelets $-133 \times 10^{9} / 1$. The creatine kinase level was $1296 \mathrm{U} / 1$ (55-170 U/1) on the $3^{\text {rd }}$ day of admission.

After a week of treatment, the patient showed clinical and biochemical improvement. He became conscious with a GCS of 15/15, and the sweating, diarrhoea and rigidity was minimal.

\section{Case Report 3}

On a humid day, a 21-year old trainee army soldier presented to Teaching Hospital, Peradeniya with exhaustion, exertional dyspnoea, high temperature, muscular rigidity and confusion following a jungle trek. The patient had experienced fever for one day, associated with cough, but had been well in the morning. Four hours into the hike, he had complained of exertional dyspnoea, faintishness and excessive fatigue.

On admission, he was drowsy with a GCS of 7/15, was tachypnoeic with an oxygen saturation of $78 \%$, blood pressure of $80 / 25 \mathrm{mmHg}$, and pulse rate of $150 / \mathrm{min}$. He was febrile with a temperature of $40.5^{\circ} \mathrm{C}$ and was rigid with opisthotonus.

He was sedated, intubated and transported to the intensive care unit for further management. His temperature rose to $42.3{ }^{\circ} \mathrm{C}$ within half an hour and a heat stroke was suspected. Physical examination and chest X-ray revealed a left sided pneumonia and a parapneumonic effusion, and there were no focal neurological signs.

He was profoundly hypotensive and required ianotropes. He was cooled using conventional methods such as antipyretics, cool intravenous fluids and placing cool wet towels and was exposed to moving air. The temperature gradually came down to $99.8^{\circ} \mathrm{F}$ within 3 hours with repeated mild fever spikes during the ensuing days which responded to antipyretics. Intravenous cefuroxime, metronidazole and clarithromycin was started to cover both community acquired and aspiration pneumonias. Urine output was maintained at approxi-mately $>100 \mathrm{ml} / \mathrm{hr}$ with adequate intravenous hydration.

Laboratory investigations on admission showed a serum creatinine of $2.1 \mathrm{mg} / \mathrm{dl}$, ALT - $82 \mathrm{u} / \mathrm{l}$ (peak $2941 \mathrm{u} / \mathrm{l}$ at day 2), AST - $118 \mathrm{u} / \mathrm{l}$ (peak $1089 \mathrm{u} / \mathrm{l}$ at day 2), bilirubin (peak) $31.29 \mathrm{mg} / \mathrm{dl}$, GGT - 442.2U/1, and blood urea $-8.9 \mathrm{mmol} / \mathrm{l}$ (peak $10.6 \mathrm{mmol} / \mathrm{l}$ at day 5). Hb was $13.3 \mathrm{~g} / \mathrm{dl}$, WBC count $6.3 \times 10^{9} / 1$ with predominant neutrophils, platelets $-128 \times 10^{9} / 1$. Urine for myoglobin became positive on day 3 , but normalized by the time of discharge. The creatine kinase level was $424 \mathrm{U} / 1$ (55-170 U/1) on admission and peaked at $17,573 \mathrm{U} / 1$ on day 6 .

The patient was extubated on day 2 , and was sent to a general medical ward on day 5, and his laboratory parameters gradually returned to normal.

\section{Discussion}

Muscular rigidity is defined as the increase in muscle tone causing resistance to externally imposed joint movements (1). This can be observed in both agonist and antagonist muscle groups, and in movements in both directions (1). Rigidity can be seen in various forms of neurological and other disorders.

Heat stroke, neuroleptic malignant syndrome and serotonin syndrome are acute medical conditions with rigidity as a presenting problem (2). They have similar manifestations and are sometimes difficult to differentiate in a clinical setting. All three are potentially life threatening, and could be fatal without timely intervention (2).

Neuroleptic malignant syndrome is characterized by hyperthermia, altered mental status, hemodynamic deregulation, rigidity, autonomic dysfunction and elevated serum creatine phosphokinase (CPK). It can be complicated by acute respiratory distress syndrome (ARDS), disseminated intravascular coagulation and ultimate multi-organ failure (3). This rare syndrome is an idiosyncratic reaction associated with the use of virtually all neuroleptics, including second-generation antipsychotics and with the abrupt withdrawal of doper- 
minergic drugs (3). It could also be associated with the use of a variety of other medications that affect central dopaminergic neurotransmission (4). The diagnosis is made by exclusion and clinical assessment. Laboratory investigations supplement the diagnosis.

The following criteria were suggested by the international consensus study of neuroleptic malignant syndrome using the Delphi method: recent dopamine antagonist exposure, or dopamine agonist withdrawal; hyperthermia; rigidity; mental status alteration; creatine kinase elevation; sympathetic nervous system lability; tachycardia plus tachypnea; and a negative work-up for other causes (5). The following critical values were identified as significant for quantitative criteria: hyperthermia, $>100.4^{\circ} \mathrm{F}$ or $>38.0^{\circ} \mathrm{C}$ on at least 2 occasions; creatine phosphokinase elevation at least 4 times the upper limit of normal; blood pressure elevation $\geq 25 \%$ above baseline; blood pressure fluctuation $\geq 20 \mathrm{~mm} \mathrm{Hg}$ (diastolic) or $\geq 25 \mathrm{~mm} \mathrm{Hg}$ (systolic) change within 24 hours; tachycardia $\geq 25 \%$ above baseline; and tachypnea $\geq 50 \%$ above baseline (5).

Treatment of NMS includes immediately ceasing the offending drug and initiating supportive measures (4). Pharmacological interventions are needed in more severe cases.

Serotonin syndrome is associated with an excess of serotonin (5HT) usually resulting from increasing the dose of a single serotonergic agonist drug, polypharmacy of serotonic agents, or a pharmacodynamic drug interaction of a monoamine oxidase inhibitor (MAOI) with a serotonin reuptake inhibitor (6). The incidence of the syndrome is rising, reflecting the growing number of serotonergic drug use in clinical practice. The incidence may also be due to an increasing diagnostic awareness of the syndrome (7). Patients with serotonin syndrome present with similar clinical features to NMS, but have a few distinguishing factors, such as spontaneous or induced clonus, severe diaphoresis and hyperreflexia (8). These patients can also present with fever, confusion, and autonomic dysfunction (8). Rigidity may manifest in severe disease (7). Hunter toxicity criteria is used in the diagnosis of serotonin syndrome as there is no definitive diagnostic test (6) [Box].

The management of serotonin syndrome involves withdrawal of the offending drugs and provision of supportive care (10). Mild cases usually resolve within 1 to 2 days with conservative treatment and removal of the causative drugs. Patients with moderate to severe cases may require hospitalization. Benzodiazepines maybe used to control agitation and tremors. Cyproheptadine, olanzapine, propranolol and chlorpromazine would be beneficial. Severely ill patients with muscular rigidity and hyperthermia will be benefited by neuromuscular paralysis, sedation, and possible intubation in an ICU setting (10).
Box. Hunter Serotonin Toxicity Criteria: Decision Rules

In the presence of a serotonergic agent:

1. IF (spontaneous clonus = yes) THEN serotonin toxicity $=$ YES

2. ELSE IF (inducible clonus = yes) AND $[($ agitation $=$ yes $)$ OR $($ diaphoresis $=$ yes $)]$ THEN serotonin toxicity $=$ YES

3. ELSE IF (ocular clonus = yes) AND $[($ agitation $=$ yes $)$ OR $($ diaphoresis $=$ yes $)]$ THEN serotonin toxicity $=$ YES

4. $\quad$ ELSE IF (tremor $=$ yes) AND (hyperreflexia $=$ yes) THEN serotonin toxicity $=$ YES

5. ELSE IF (hypertonic = yes) AND (temperature $>$ $38^{\circ} \mathrm{C}$ ) AND [(ocular clonus = yes) OR (inducible clonus $=$ yes $)]$ then serotonin toxicity $=$ YES

6. ELSE serotonin toxicity $=$ NO

Hyperthermia, with an increase in core body temperature, associated with a number of cerebral impairments (varying from slight confusion, delirium to coma) and hypo or anhiderosis, is termed a heat stroke (11). There are two recognized forms of heat stroke. Post exertion heat stroke occurs in the young, following prolonged physical exercise. Non exertion or classic heat stroke is seen in the elderly, the debilitated and the very young, during heat waves (11). Concomitant illness, dehydration, and poor acclimatization can increase the susceptibility to a heat stroke (11).

These patients are normally in a hyperdynamic state (11). A majority have a tachycardia with a rate of more than 130 beats per minute, with episodes of cardiac arrhythmias. Cerebral dysfunction is a major criterion for diagnosing heat stroke and therefore present in all patients. This could be trivial, as in mild impairment of judgement or could manifest as delirium, seizures or coma (12). Patients may have either decerebrate or decorticate rigidity. Most patients have features of hepato-cellular damage, which infrequently may lead to fulminant hepatic failure. Dehydration, volume depletion, myoglobinuria and resultant renal toxicity may lead to acute renal failure (12).

The initial treatment of heat stroke involves stabilization in a cool area (12). Factors leading to heat exhaustion need to be corrected promptly. Evaporative cooling may be necessary. Monitoring the electrolyte status and core temperature is a must (12). A tertiary care facility would be needed for patients with significant dehydration, hyponatremia, or who have mental status changes or central nervous system irritability (12). Oral rehydration with sodium may be useful (13). It is essential to recognize the features of hyponatremic heat exhaustion and avoid administering hypotonic fluids (12). Gradual repletion of 
sodium with normal saline is important (13). The symptoms of heat stroke often resolve within two to three hours (13).

Table 1 compares and contrasts the principal characteristics of the three diseases discussed in this case series.

Table 1. Comparison of the principal characteristics of neuroleptic malignant syndrome, serotonin syndrome and heat stroke

\begin{tabular}{|c|c|c|c|}
\hline Variable & $\begin{array}{l}\text { Neuroleptic malignant } \\
\text { syndrome }\end{array}$ & Serotonin syndrome & Heat stroke \\
\hline \multirow{6}{*}{$\begin{array}{l}\text { Common } \\
\text { Features }\end{array}$} & Fever & Fever & Fever \\
\hline & Delirium & Delirium & Delirium \\
\hline & Autonomic instability & Autonomic instability & $\mathrm{N} / \mathrm{A}$ \\
\hline & Tremor & Tremor & Tremor \\
\hline & Diaphoresis & Diaphoresis & $\mathrm{N} / \mathrm{A}$ \\
\hline & Elevated CPK & Elevated CPK & Elevated CPK \\
\hline \multirow[t]{4}{*}{$\begin{array}{l}\text { Distinguishing } \\
\text { features }\end{array}$} & $\begin{array}{l}\text { Lead pipe or cogwheel } \\
\text { rigidity }\end{array}$ & $\begin{array}{l}\text { Myoclonus } \\
\text { rigidity }\end{array}$ & Decerebrate/decorticate \\
\hline & & Hyperreflexia & \\
\hline & $\mathrm{N} / \mathrm{A}$ & $\mathrm{N} / \mathrm{A}$ & Anhiderosis \\
\hline & & Diarrhoea & $\mathrm{N} / \mathrm{A}$ \\
\hline \multirow[t]{4}{*}{$\begin{array}{l}\text { Associated } \\
\text { medications }\end{array}$} & $\begin{array}{l}\text { Typical antipsychotics } \\
\text { (e.g., haloperidol) }\end{array}$ & $\begin{array}{l}\text { SSRIS } \\
\text { (e.g., fluoxetine) }\end{array}$ & $\mathrm{N} / \mathrm{A}$ \\
\hline & $\begin{array}{l}\text { Atypical antipsychotics } \\
\text { (e.g., risperidone, } \\
\text { quetiapine, olanzaqpine) }\end{array}$ & $\begin{array}{l}\text { SNRIs } \\
\text { (e.g., venalafaxine) }\end{array}$ & \\
\hline & Metoclopropramide & $\begin{array}{l}\text { Tricyclic } \\
\text { antidepressants } \\
\text { (e.g., amitriptyline) }\end{array}$ & \\
\hline & Levodopa withdrawal & $\begin{array}{l}\text { MAOIs } \\
\text { (e.g., moclobemide, } \\
\text { phenylzine) }\end{array}$ & \\
\hline \multirow[t]{6}{*}{ Management } & $\begin{array}{l}\text { Discontinue offending } \\
\text { medications }\end{array}$ & $\begin{array}{l}\text { Discontinue offending } \\
\text { medications }\end{array}$ & $\begin{array}{l}\text { Physical cooling } \\
\text { methods }\end{array}$ \\
\hline & $\begin{array}{l}\text { Hydration / supportive } \\
\text { measures }\end{array}$ & $\begin{array}{l}\text { Hydration / supportive } \\
\text { measures }\end{array}$ & $\begin{array}{l}\text { Hydration/supportive } \\
\text { measures }\end{array}$ \\
\hline & Bromocriptine & Cyproheptadine & Dantrolene \\
\hline & Amantadine & Methysergide & \\
\hline & Dantrolene & Chlorpromazine & \\
\hline & Electroconvulsive therapy & & \\
\hline
\end{tabular}

$\mathrm{CK}=$ creatine kinase $\mathrm{MAOI}=$ monoamine oxidase inhibitor $; \mathrm{SNRI}=$ serotonin/norepinephrine reuptake inhibitor; SSRI = selective serotonin reuptake inhibitor 


\section{Conclusions}

In this case series we have discussed three clinical scenarios, which can present with rigidity as the crucial clinical feature. A high degree of clinical suspicion is needed to arrive at a proper diagnosis. The management should be individualized accordingly to prevent the complications of these life threatening medical conditions.

\section{Conflicts of interest}

None declared

RP Bandara, Consultant Physician, Senior Lecturer, Department of Medicine, Faculty of Medicine, University of Peradeniya, Sri Lanka

A Ellepola, Consultant Psychiatrist, Teaching Hospital, Anuradhapura, Sri Lanka

Corresponding author: A Ellepola

Email: anu.ellepola@gmail.com

(iD http://orcid.org/0000-0001-9699-2777

\section{References}

1. Sanger TD, Delgado MR, Gaebler-Spira D, Hallett M, Mink JW. Task Force on Childhood Motor Disorders. Classification and definition of disorders causing hypertonia in childhood. Pediatrics. 2003; 111(1): e89-97.
2. Sokoro AA, Zivot J, Ariano RE. Neuroleptic Malignant Syndrome Versus Serotonin Syndrome: The Search for a Diagnostic Tool. The Annals of Pharmacotherapy, 2011; 45(9): e50.

3. Seitz DP. Diagnostic uncertainty in a case of neuroleptic malignant syndrome. CJEM. 2005; 7(4): 266-272.

4. Berman BD. Neuroleptic Malignant Syndrome. Neurohospitalist. 2011; 1 (1): 41-7.

5. Gurrera RJ, Caroff SN, Cohen A, et al. An international consensus study of neuroleptic malignant syndrome diagnostic criteria using the Delphi method. J Clin Psychiatry. 2011; 72(9): 1222-8.

6. Sternbach H. The serotonin syndrome. Am J Psychiatry 1991; 48(6): 705-13.

7. Hall M, Buckley N. Serotoine Syndromme. Aust Prescr 2003; 26: 62-63.

8. Perry PJ, Wilborn CA. Serotonin syndrome vs neuroleptic malignant syndrome: a contrast of causes, diagnoses, and management. Ann Clin Psychiatry 2012; 24(2): 155-62.

9. Dunkley EJ, Isbister GK, Sibbritt D, Dawson AH, Whyte IM. The Hunter Serotonin Toxicity Criteria: simple and accurate diagnostic decision rules for serotonin toxicity. QJM. 2003; 96(9): 635-42.

10. Frank C. Recognition and treatment of serotonin syndrome. Can Fam Physician 2008; 54(7): 988-992.

11. Lee-Chiong TL Jr, Stitt JT. Heatstroke and other heatrelated illnesses. The maladies of summer. Postgrad Med 1995; 98: 26-8,31-3,36

12. Glazer JL. Management of Heatstroke and Heat Exhaustion. Am Fam Physician 2005; 71(11): 2133-40.

13. Barrow MW, Clark KA. Heat-related illnesses. Am Fam Phys 1998; 58: 749-5. 